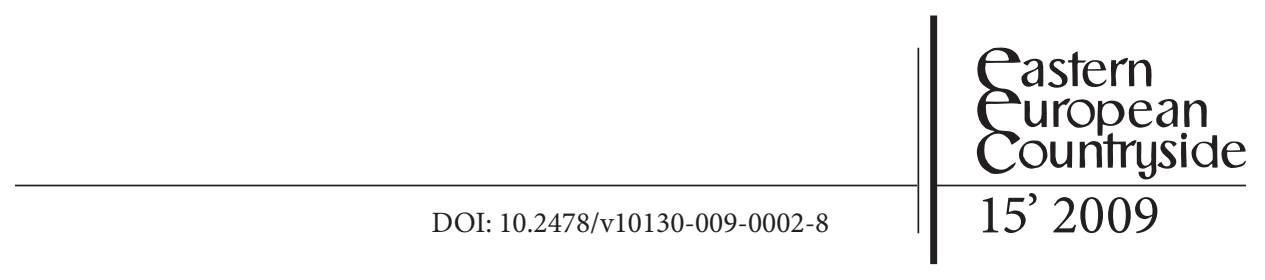

László J. Kulcsár, David L. Brown

\title{
Public Perceptions of Population Changes in Hungary
}

\begin{abstract}
This study examines the public perceptions of population dynamics in Hungary. Based on a representative national sample survey from 2005, we discuss how the general public perceives demographic trends and attitudes people have towards the possible reasons behind these trends and solutions they believe are appropriate to contend with the trends. Rural populations were expected to have poorer knowledge of current population trends and changes and more conservative attitudes toward controversial demographic issues, but this expectation was not supported by the data. Since relatively little research has been conducted on population literacy, this study contributes to a better understanding of how public perceptions on population are formed and how this knowledge and attitudes may affect public policy addressing demographic trends.
\end{abstract}

Keywords: Population change, Hungary, demography, public opinion, population literacy

\section{Introduction and Background}

This paper examines public perceptions of population changes in Hungary in 2005. Like the rest of Europe, Hungary has experienced important demographic changes since 1990. Its population has declined in size, aged and become less concentrated in the central parts of large cities. These changes have important impacts on the nation's social, political and economic life, and for public policies designed to target regional development, assist older populations, control immigration and provide support for families. In a democratic 
nation, where policy is supposed to respond to public sentiments and needs, it is important that citizens have a basic knowledge of population dynamics, and the relationships of these trends and changes on social well being. At the same time, incorrect perceptions of population trends can support unmerited policies and drive policy making in the wrong direction. This research examines Hungarian perceptions of and attitudes towards recent population trends and changes.

Very little research has focused on "population literacy”, the public's knowledge of population trends and policies. This lack of research seems strange since as the Population Reference Bureau observes, informing people about population, health and the environment empowers them to use that information to advance the well-being of current and future generations (Population Reference Bureau, 2009). While research is generally lacking on this issue, several important studies have been conducted. Perhaps the largest-scale study of this kind was conducted by the Rand Corporation. Rand conducted a national survey in the U.S. to examine American attitudes about economic assistance overseas and priorities for targeting U.S. aid; knowledge and views of global demographic facts and trends; and views on specific issues, including family planning programmes, abortion and congressional actions on population-policy measures. Their publication, „How Americans View Population Issues" found that the American public is only mildly interested in demographic issues and has a limited sense of the current dimensions of world population. For example, only 14 per cent accurately reported world population size in the five-to-six billion range. The authors concluded that while most Americans lack knowledge about the world's population size and growth rate they are nonetheless concerned about global population growth and its possible consequences. (Adamson et al. 2000).

In another study, the Society of Actuaries (2006) studied demographic knowledge among individuals aged 45 to 80 to determine if workers could accurately assess their life expectancy. They reasoned that workers could undersave if they underestimated their remaining years of life. They reasoned that demographic literacy as well as financial literacy might be a source of problems in individuals' retirement planning. They found that roughly 40 per cent of pre-retirees underestimated life expectancy by five or more years. Similarly, a British study found that on average people over a range of ages underestimated their life expectancy by 4.6 years for males and 6.0 years for females. Respondents aged 30 to 39 , an age range where they may be considering employment providing pension coverage, underestimated their life expectancy 
by almost six and a half years (O'Brien et al 2005). These findings suggest that a substantial portion of the population may be considerably underestimating its life expectancy. However, the topic of accuracy of life expectancy expectations is not settled. Others found that a sample of males with an average age of 50 overestimated their life expectancy by three years on average, while a similar sample of females overestimated their age on average by about 6 months (Puri and Robinson 2005). Yet another study using the U.S. Health and Retirement Survey indicates that persons in or near retirement on average have fairly accurate expectations of life expectancy (Gong and Webb 2006).

Population literacy is especially important at times when certain population trends create significant concerns for a large number of people. This occurred in the 1960s and 1970s when the fear of global overpopulation created substantial, albeit largely uninformed, public concern. In fact, the numbers later proved that public tension was highest when fertility rates had already begun their declining trajectory. Soon after this "good news" became widely reported by the media, public interest in overpopulation declined (Wilmoth and Ball 1992).

Immigration, especially unauthorized immigration, is a more recent example of a public driven concern with population change. The public typically has an unreliable picture of both the stock and the flow of immigrants, which tends to lead to an overestimation of the number of immigrants, concerns about their impact on the price and availability of labour, and the emergence of a perception that immigration is a widespread problem. If this occurs in countries where immigrants are visibly different from the indigenous population, where their socioeconomic status is lower, or where the host country has its own population problem (for example, persistent low fertility and/or net out migration), public opposition to immigration can run high. A good example of this was the month long rioting in France in 2005. Due to extensive media coverage, the public understood the main forces behind the riots, such as immigrant discrimination, inefficient policies and difficult integration behind the riots. However, their opinions were not informed by empirical information about the stock and flow of immigration since the French census does not allow questions on race and ethnicity. Hence, no reliable estimates existed on the actual number of immigrants, their origins and relative socioeconomic status. This lack of reliable information made it more difficult to settle public tensions.

To finish with a Hungarian example, a national uproar was created in 2007 when a study was leaked that examined Asian immigration as a potential 
tool to offset the nation's population decline. Soon, with typical reductionism, the Hungarian media was loud to comment on the public fear of "inviting a million Chinese" (HVG 2008). This discourse then fuelled other political agendas that had nothing to do with population dynamics, effectively hindering a reasonable discourse on the implications of immigration for the country's population growth rate or potential changes in its demographic composition.

Hence, there is ample evidence that throughout the world people are likely to lack reliable information about population size, growth and/or composition, but also to have strong views about what they perceive to be population problems, and what to do about them. With that in mind, we briefly review Hungary's recent population dynamics and then examine the extent to which Hungarians are aware of major trends as well as their attitudes towards these trends and changes as social and political issues meriting government attention. In addition, it is a mistake to assume that Hungary's population is homogeneous and evenly spread across the country. In fact, over one third of Hungary's population still lives in rural areas (Population Reference Bureau 2006), and there is socioeconomic diversity. Hence, it is reasonable to expect that knowledge of and attitudes towards population will differ across socioeconomic status and between persons living in urban and rural areas. Rural persons, in particular, are thought to have less access to media that convey population-related information, and rural persons are generally seen as more conservative on social issues than their urban counterparts. Accordingly, one would expect rural persons to have less knowledge about population matters and to express more conservative attitudes about what to do about population trends they define as social problems. Accordingly, our analysis will examine whether rural-urban residence and socioeconomic status affect people's perception of population matters.

\section{Hungary's Population Dynamics}

Hungary like other ex-socialist countries has experienced dramatic changes in population dynamics since the regime change in 1990. These demographic changes are partly the result of transformation in the nature and location of employment since 1990, post-socialist legacies, the withering welfare state particularly as this affects women's roles, the average age at which women have their first child, and family size norms (Brown and Kulcsar 
2000). These demographic changes can be grouped into three categories: (a) long-term population decline, (b) population aging, and (c) population deconcentration.

By 2008, Hungary's population stood at 10.03 million, a decline of 5.5 per cent since 1985. Moreover, it is projected to shrink to 9.6 million by midcentury (Population Reference Bureau 2008). This decline is a result of low fertility and a slight increase in net out migration. The nation's total fertility rate in 2006 stood at 1.35 children per woman, slightly higher than in previous years, but still far below generational replacement. Even if this rate is adjusted for the "tempo effect", e.g. the average age at which women have their first birth, women are only bearing 1.75 children each (Lutz et al. 2008).

Like the rest of Europe, and in fact the rest of the world, Hungary's population is becoming older. The percentage of 65 -year-olds and above was almost 16 in 2007 and is expected to rise to over 22 per cent by 2030. Aging in Hungary is a result of prolonged low fertility, an increase in longevity, and a slight net out migration of young adults. After an initial decline after the regime change (for men not women), Hungary's life expectancy has now risen to 73.2 years. While this is slightly lower than the average for the EU27, Hungary's expectation of life at birth has become more comparable to the continental average (Population Reference Bureau 2008).

The population became less concentrated in the centres of large cities in Hungary after 1990. While the data seemed to show that this resulted from the post-socialist economic transformation, in fact, the deconcentration trend began much earlier and is a legacy of socialist development policies beginning around 1968 (Brown et al. 2005). Post-socialist population deconcentration involves both suburbanization around Budapest and several other large cities as well as net movement to villages, especially those with relatively easy access to larger places.

While Hungary is similar to other ex-socialist countries in both its politicaleconomic transformation and its contemporary population dynamics, it would be an exaggeration to say that there is one pattern of Eastern European demographic change. Rather than having one post-socialism, we can say that there are several distinct post-socialisms (Stark and Brust 1998). Local characteristics, such as historic legacies, institutional variations, political and demographic regimes and other components alter the general social and population trends by which Eastern Europe slowly converges to the European mainstream. 


\section{Public Perceptions of Population Trends and Changes}

\section{Data and Methods}

As mentioned before, the general public seldom has a good understanding of demographic trends and mechanisms, but their perception of these dynamics, even if uninformed, can affect policy discourse and policy development. In this section, the analysis will focus on data from a national social survey conducted in Hungary in 2005. The survey was conducted by the Echo Survey Institute in November of that year, targeting Hungarian citizens $18+$ years old. A nationally representative sample of 973 respondents was selected by stratified sampling along three key characteristics: sex, age, education. To ensure spatial representativeness, the sample was clustered along the counties and along the nation's major urban classification. While this survey was not designed with the intention of systematically measuring public opinion on demographic trends, a separate section of the questionnaire was provided for this purpose. Respondents were asked about their knowledge of demographic dynamics in the past 15 years in Hungary as well as their possible concerns about the implications of these trends and changes. This is the first analysis of these data.

\section{Findings}

Population knowledge: As shown in Table 1, most people indicated that fertility declined during the 1990s. Similarly, the data show a widespread perception that Hungary experienced population decline during this period. Both of these observations correspond with the real change, and both issues have received significant publicity since the late 1980s, irrespective of the prevailing political regimes. Most respondents were also correct that mortality increased while the number of marriages declined.

At the same time, there was considerable confusion regarding perceived trends of migration and internal population redistribution. People were generally divided as to whether domestic migration increased or remained unchanged. In reality, the volume of domestic migration was relatively low and remained largely unchanged during the 1990s. At the same time people were aware of the steep decline in urban industrial jobs, the development of western style suburbs around Budapest and several other cities, and some return to rural 
Table 1. Public perception of demographic dynamics (\%)

\begin{tabular}{|l|c|c|c|c|c|c|c|c|c|}
\hline \multirow{2}{*}{$\begin{array}{c}\text { Demographic } \\
\text { dynamics }\end{array}$} & \multicolumn{3}{|c|}{ Increased } & \multicolumn{3}{c|}{ No change } & \multicolumn{3}{c|}{ Decreased } \\
\cline { 2 - 12 } & Total & Urban & Rural & Total & Urban & Rural & Total & Urban & Rural \\
\hline Population size & 5 & 5 & 6 & 7 & 5 & 10 & 86 & 89 & 84 \\
\hline Fertility & 4 & 4 & 4 & 6 & 5 & 7 & 89 & 91 & 89 \\
\hline Mortality & 75 & 76 & 80 & 19 & 22 & 17 & 2 & 2 & 3 \\
\hline Internal migration & 45 & 50 & 48 & 44 & 47 & 48 & 3 & 4 & 3 \\
\hline Emigration & 60 & 65 & 63 & 28 & 30 & 31 & 5 & 4 & 7 \\
\hline Immigration & $71 *$ & 76 & 73 & 21 & 22 & 21 & 3 & 2 & 6 \\
\hline $\begin{array}{l}\text { Immigration of } \\
\text { marriages }\end{array}$ & 5 & 6 & 5 & 14 & 14 & 14 & 77 & 80 & 81 \\
\hline
\end{tabular}

${ }^{*} \mathrm{p}<0.05 ;{ }^{* *} \mathrm{p}<0.01$ (Denoting statistically significant differences between urban and rural responses)

Source: National Social Survey 2005, Echo Survey Institute.

areas as a refuge against urban industrial restructuring. These transformations occurred and new phenomena were discussed in the popular media, but they did not result in much net redistribution of population between regions or rural vs. urban areas. Accordingly, it is unsurprising that many respondents felt that domestic migration had intensified even though this is not true.

The same reason can be found behind the public perception of international migration. Almost two thirds (60 per cent) of respondents believed that emigration from Hungary increased, and 71 per cent assumed that immigration to Hungary had increased. Technically both are true compared to the closed system of socialism as today there are more people leaving and entering the country. However, neither in- nor out-migration is significant compared to some other Eastern European countries ${ }^{1}$. It is likely that both phenomena have a low social perception threshold, and this is exacerbated by the popular media. Framing issues like the presence of illegal Hungarian workers in Western Europe or the Hungarian brain drain in a problem oriented manner made people think that Hungary is experiencing large-scale emigration. At the same time, stories of immigrant worker flows from abroad, displaced populations from the former Yugoslavia amidst high unemployment as well as the appearance of dark-skinned people on Hungary's streets may lead people to the otherwise incorrect conclusion that the country is experiencing rampant immigration.

1 Romania, Bulgaria and Poland have significant outmigration, while Slovenia and the Czech Republic has positive net migration trends (European Demographic Data Sheet, 2008). 
In summary then, Hungarians have a reasonably accurate sense of the nation's population dynamics although they tend to overestimate the volume of migration into and out of cities and into and out of the nation. We examined the impact of rural-urban residence on public knowledge of population trends and changes assuming that rural people would have less formal education, less concern for national level issues, and less reliable information on these subjects. As shown in Table 1, place of residence has virtually no impact on population knowledge. Rural persons are just as likely to be well or poorly informed as their urban counterparts.

Public attitudes towards population issues: Respondents were asked to indicate their agreement with 14 statements regarding social issues on demographic change. These responses ranged from 1 (fully disagree) to 4 (fully agree). Table 2 shows the mean value of agreement as well as dispersion around

Table 2. Agreement with statements on demographic issues

\begin{tabular}{|l|c|c|c|}
\hline \multicolumn{1}{|c|}{ Statements on demographic issues } & Mean* & St.Dev. & $\begin{array}{c}\text { Per cent } \\
\text { agree or } \\
\text { strongly } \\
\text { agree }\end{array}$ \\
\hline With economic growth, people would have more children & 3.38 & .76 & 88.0 \\
\hline Population decline is very dangerous for national interests & 3.24 & .79 & 86.3 \\
\hline $\begin{array}{l}\text { Many Hungarians leave the country to find a better life } \\
\text { elsewhere }\end{array}$ & 3.19 & .80 & 82.4 \\
\hline $\begin{array}{l}\text { Due to the adaptation of Western culture less and less } \\
\text { people marry }\end{array}$ & 3.09 & .86 & 79.0 \\
\hline $\begin{array}{l}\text { The government shouldn't allow large immigration from the } \\
\text { Third World }\end{array}$ & 3.05 & .88 & 75.2 \\
\hline Overpopulation is among the biggest problems in the world & 2.91 & .95 & 71.3 \\
\hline Women should stay at home to raise children & 2.82 & .99 & 63.9 \\
\hline The problem is that poor people have many children & 2.74 & .98 & 61.3 \\
\hline It is impossible to influence population trends with policy & 2.66 & .99 & 58.3 \\
\hline More people move to cities than to the countryside & 2.65 & .93 & 59.7 \\
\hline $\begin{array}{l}\text { Hungarians are more likely to commit suicide than other } \\
\text { European people }\end{array}$ & 2.50 & .98 & 54.0 \\
\hline Immigration can help to stop population decline & 2.22 & .92 & 38.2 \\
\hline $\begin{array}{l}\text { Aging will not be a big burden on society, because the state } \\
\text { could spend less on education }\end{array}$ & 1.85 & .90 & 23.7 \\
\hline Having children out of wedlock is unacceptable & 1.71 & .93 & 19.6 \\
\hline
\end{tabular}

* Scores range between 1 and 4; higher scores indicate agreement with the statement Source: National Social Survey 2005, Echo Survey Institute. 
Table 3. Agreement with statements on demographic issues

\begin{tabular}{|l|c|c|c|c|}
\hline \multicolumn{1}{|c|}{ Statements on demographic issues } & \multicolumn{2}{c|}{ Urban } & \multicolumn{2}{c|}{ Rural } \\
\cline { 2 - 5 } & Mean & St.Dev. & Mean & St.Dev. \\
\hline $\begin{array}{l}\text { With economic growth, people would have more } \\
\text { children }\end{array}$ & 3.41 & .74 & 3.33 & .80 \\
\hline $\begin{array}{l}\text { Population decline is very dangerous for national } \\
\text { interests }\end{array}$ & 3.24 & .77 & 3.21 & .81 \\
\hline $\begin{array}{l}\text { Many Hungarians leave the country to find a better } \\
\text { life elsewhere }\end{array}$ & 3.17 & .81 & 3.24 & .76 \\
\hline $\begin{array}{l}\text { Due to the adaptation of Western culture less and } \\
\text { less people marry* }\end{array}$ & 3.01 & .89 & 3.23 & .75 \\
\hline $\begin{array}{l}\text { The government shouldn't allow large immigration } \\
\text { from the Third World }\end{array}$ & 3.04 & .88 & 3.07 & .87 \\
\hline $\begin{array}{l}\text { Overpopulation is among the biggest problems in } \\
\text { the world }\end{array}$ & 2.91 & .96 & 2.91 & .92 \\
\hline Women should stay at home to raise children & 2.81 & .96 & 2.83 & 1.04 \\
\hline $\begin{array}{l}\text { The problem is that poor people have many } \\
\text { children }\end{array}$ & 2.74 & .97 & 2.72 & .99 \\
\hline $\begin{array}{l}\text { It is impossible to influence population trends with } \\
\text { policy }\end{array}$ & 2.65 & 1.01 & 2.67 & .96 \\
\hline More people move to cities than to the countryside* & 2.70 & .94 & 2.53 & .90 \\
\hline $\begin{array}{l}\text { Hungarians are more likely to commit suicide than } \\
\text { other European people }\end{array}$ & 2.46 & 1.00 & 2.55 & .94 \\
\hline Immigration can help to stop population decline & 2.23 & .92 & 2.19 & .91 \\
\hline $\begin{array}{l}\text { Aging will not be a big burden on society, because } \\
\text { the state could spend less on education* }\end{array}$ & 1.79 & .90 & 1.94 & .89 \\
\hline Having children out of wedlock is unacceptable** & 1.60 & .85 & 1.91 & 1.04 \\
\hline
\end{tabular}

Scores range between 1 and 4; higher scores indicate agreement with the statement $\mathrm{p}<0.05 ;{ }^{* *} \mathrm{p}<0.01$

Source: National Social Survey 2005, Echo Survey Institute.

this average, and the percentage of persons agreeing or strongly agreeing with each item. There are five items with 75+ per cent support among Hungarians. Only 12 per cent disagree with the statement that people would have more children if the economy grew. This indicates that Hungarians view fertility as driven by economic factors. Respondents also gave relatively strong support to the statement that population decline endangers the nation's interests. The data seem to indicate that Hungarians blame the current population decline on the adoption of western culture, e.g. via low marriage rates, and on Hungary's relative lack of economic opportunities compared with countries which attract Hungarian immigrants. 
As indicated earlier, we found virtually no difference in population knowledge when we disaggregated the data by rural-urban residence (Table 1). Similarly, the data in Table 3 show that attitudes towards population issues and potential population policies are largely the same regardless of where one lives. We found that urbanites, even with higher educational attainment (data not shown), were no different in assessing the major demographic trends. This is surprising since a number of these items tap attitudinal realms such as immigration, high fertility among poorer persons and intergenerational equity in public spending on youth and elders where the generally more conservative nature of rural communities would be expected to produce more conservative opinions. Contrary to our expectations, there were only a few items out of the 14 which showed significant rural-urban differences (Table 3). Rural residents were more likely to say that western norms lead to the decline of marriages and that childbearing out of wedlock is unacceptable. Both of these are expected differences stemming from the more conservative nature of the countryside. Urban residents, on the other hand, were slightly more convinced that people are moving to cities. This is an interesting finding because one would expect rural residents to be more sensitive to rural depopulation.

Cluster analysis: It is difficult to describe Hungary's overall opinion on population matters from 14 separate indicators. Accordingly, we used cluster analysis to reveal the underlying dimensions and structures of responses across various groups of respondents. The data in Table 4 show the cluster centres and $\mathrm{F}$ values for opinions on the 14 population-related statements. As a rule of thumb, cluster centres of 3.0 and higher contribute to describing the sub-population's overall attitude regarding population matters.

We have labelled Cluster 1 "problem-rejecting". Respondents described by this cluster of attitudes do not consider demographic trends to be significant threats to national interests; they see fewer problems and they have more confidence in population policies. Cluster 1 is the smallest of the three clusters containing about $1 / 4$ of the weighted cases. Cluster 2 was labelled as "alarmistliberal". Respondents in this cluster perceive demographic problems as adversely affecting Hungary, but at the same time take a liberal stand regarding the situation of women and immigration to Hungary from the Third World. Cluster 3, the largest of the three clusters making up almost 50 per cent of the sample, is the best defined across the various models. We labelled this group "alarmist-conservative", as respondents clearly identify demographic dynamics as problems, and take a very conservative stand regarding what should be done about this including limiting Third World immigration, proposing that women 
Table 4. Cluster analysis of opinions on demographic issues

\begin{tabular}{|c|c|c|c|c|}
\hline \multirow[b]{2}{*}{ Opinions on demographic issues } & \multicolumn{3}{|c|}{ Clusters } & \multirow[b]{2}{*}{ F value } \\
\hline & $\begin{array}{l}\text { "Problem } \\
\text { rejecting" }\end{array}$ & $\begin{array}{c}\text { "Alarmist- } \\
\text { liberal" }\end{array}$ & \begin{tabular}{|c|} 
"Alarmist- \\
conservative"
\end{tabular} & \\
\hline $\begin{array}{l}\text { Overpopulation is among the biggest } \\
\text { problems in the world }\end{array}$ & 1.86 & 3.28 & 3.25 & 234.618 \\
\hline $\begin{array}{l}\text { Women should stay at home to raise } \\
\text { children }\end{array}$ & 2.72 & 2.09 & 3.40 & 150.948 \\
\hline $\begin{array}{l}\text { Hungarians are more likely to commit } \\
\text { suicide than other European people }\end{array}$ & 1.64 & 2.55 & 2.86 & 113.899 \\
\hline $\begin{array}{l}\text { The problem is that poor people have } \\
\text { many children }\end{array}$ & 2.22 & 2.57 & 3.23 & 78.872 \\
\hline $\begin{array}{l}\text { The government shouldn't allow large } \\
\text { immigration from the Third World }\end{array}$ & 2.78 & 2.61 & 3.37 & 59.560 \\
\hline $\begin{array}{l}\text { Due to the adaptation of Western } \\
\text { culture less and less people marry }\end{array}$ & 2.62 & 3.09 & 3.29 & 36.370 \\
\hline $\begin{array}{l}\text { More people move to cities than to the } \\
\text { countryside }\end{array}$ & 2.53 & 2.35 & 2.94 & 28.058 \\
\hline $\begin{array}{l}\text { Many Hungarians leave the country to } \\
\text { find a better life elsewhere }\end{array}$ & 3.24 & 2.82 & 3.31 & 25.382 \\
\hline $\begin{array}{l}\text { It is impossible to influence population } \\
\text { trends with policy }\end{array}$ & 2.22 & 2.81 & 2.82 & 25.260 \\
\hline $\begin{array}{l}\text { Aging will not be a big burden on } \\
\text { society, because the state could spend } \\
\text { less on education. }\end{array}$ & 1.70 & 1.69 & 2.13 & 19.991 \\
\hline $\begin{array}{l}\text { Having children out of wedlock is } \\
\text { unacceptable }\end{array}$ & 1.63 & 1.43 & 1.94 & 19.832 \\
\hline $\begin{array}{l}\text { If the economy grew, people would } \\
\text { have more children }\end{array}$ & 3.27 & 3.16 & 3.51 & 13.556 \\
\hline $\begin{array}{l}\text { Population decline is very dangerous } \\
\text { for national interests }\end{array}$ & 3.01 & 3.19 & 3.35 & 9.679 \\
\hline $\begin{array}{l}\text { Immigration can help stop population } \\
\text { decline }\end{array}$ & 2.12 & 2.19 & 2.42 & 7.051 \\
\hline Weighted N & 167 & 200 & 301 & \\
\hline Weighted\% & 25.0 & 29.9 & 45.1 & \\
\hline
\end{tabular}

Source: National Social Survey 2005, Echo Survey Institute.

should stay at home, and blaming social problems on the high fertility of the poor. Interestingly, however, there is universal agreement that Hungarians would have more babies if the economy improved, and there appears to be universal disagreement that immigration can be a substitute for current low 
fertility among Hungarians. Also, there is virtually no support for the idea that population growth can be influenced by government policy.

There are important and interesting differences regarding the sociodemographic characteristics of respondents in the three clusters. "Problemrejecters" are more likely to be women, people in their twenties or over 70, with lower than high school education. In contrast, the "alarmist-liberals" are likely to be under 40 years of age, have a university degree and come from higher status families (defined by the father's educational attainment). They are more likely to live in Budapest and have higher income. Finally, the "alarmistconservatives" are more likely to be middle-aged men, live in small towns or rural areas, and have two or more children. While "alarmist-conservatives" do not have especially low educational attainment, respondents in this cluster are more likely to have low parental education. "Alarmist-conservatives" are also more likely to live in east Hungary, either in the traditionally agricultural region of the Great Plains or in the less developed north-eastern mountainous counties. With respect to the urban and rural differences in the cluster analysis, the pattern is mainly between Budapest and the rest of the country.

\section{Conclusion}

Hungarians appear to have a reasonable knowledge of their nation's recent population dynamics. Most are aware that their population is declining, that fertility is low by historical standards, that the marriage rate has declined and that mortality has increased. In contrast, they appear to overestimate the volume of international migration, and they only have a vague notion about internal migration and population redistribution. Our analysis appears to suggest that incorrect knowledge about immigration trends contributes to about three quarters of Hungarians defining population change in general, and immigration from Third World nations in particular as a problem. Rural persons appear to hold somewhat more conservative attitudes on demographic matters, but this seems to be mostly a Budapest versus the rest of the nation phenomenon. Given the sensitivity of issues such as Third World immigration, unwed childbearing, low marriage rates and perceived high fertility among poor persons, we had expected rural persons to strongly support more conservative positions. On demographic matters, at least, rural Hungarians are less conservative than one might have imagined. 
Being an alarmist is one thing, while supporting various policy measures is another especially if the public approach to possible policy solutions is quite diverse. It seems that most of the Hungarian public has conservative views on demographic trends and their societal and policy consequences. This should not be surprising in a country that experienced everyday stresses at the micro level and macro level population decline for decades. Having acknowledged this historical legacy, it is not easy to find effective models for population policy in the current developmental context. And it is especially difficult to articulate a coherent population policy when the country is tumbling between two very strong forces - the ever increasing ideational change of the second demographic transition and the still deteriorating economic conditions 20 years after the regime change.

The implications of these survey findings are noteworthy. Even with gradually improving mortality and a very slow reversal of declining fertility trends, immigration is the only realistic way of addressing population decline in the foreseeable future. However, examining public opinion on various statements, it seems that while Hungarians recognize the country's population decline, they perceive it as a danger for national interests and believe that many Hungarians leave the country to find a better life elsewhere, they are still very cautious about foreign immigration as a potential solution. Unfortunately for them, while a country can decide who to let in, it cannot determine the pool from which admitted immigrants are chosen. In the Hungarian case, with the decline of ethnic Hungarian immigration from neighbouring countries, the country mostly receives immigrants from less developed regions, and these immigrants are often unwelcome. Thus, corresponding with the media discourse, the survey results indicate that the Hungarian public is not yet prepared to embrace immigration as a solution to the country's population decline.

\section{Acknowledgments}

The authors would like to acknowledge the help of Tamas Domokos who provided access to the survey, as well as the USDA W2001 research project and the Kansas Population Centre for supporting this research. 


\section{References}

Adamson, D., N. Belden, J. De Vanzo, and S. Patterson, How Americans View World Population Issues: A Survey of Public Opinion. Santa Monica 2000: Rand Corporation.

Brown, D.L., L.J. Kulcsar, L. Kulcsar, C. Obadovics, Post-Socialist Restructuring and Population Redistribution in Hungary. Rural Sociology, no 70(3), 2005, pp. 336-359.

Brown, D.L. and L. Kulcsar, Rural families and Rural Development in Central and Eastern Europe. Eastern European Countryside, vol. 6, 2000, pp. 5-23.

Gong, Guan and Webb, Anthony., Mortality Heterogeneity and the Distributional Consequences of Mandatory Annuitization. CRR WP 2006/11. Boston College 2006: Center for Retirement Research.

HVG, Bevándorlás Magyarországra [Immigration to Hungary]. November 24, 2008.

Lutz, W., M. Mamolo, M. Potancokovo, T. Sobotka, European Demographic Data Sheet: 2008. Vienna 2008: International Institute for Applied Systems Analysis. www.populationeurope.org.

O'Brien, C., Fenn, P., and Diacon, S., How Long Do People Expect to Live? Results and Implications. CFIS Research Report No. 2005. Centre for Risk and Insurance Studies, 2005.

Population reference Bureau, Annual Report, 2008. Washington 2009, DC.

Population Reference Bureau,'Hungary', in: World Population Data Sheet. Washington 2006, DC, http://www.prb.org/Countries/Hungary.aspx.

Population Reference Bureau, European Demographic Data Sheet, 2008. Washington 2008, DC, www.populationeurope.org.

Puri, M. and Robinson, D., Optimism and Economic Choice. NBER Working Paper No. 11361, 2005.

Society of Actuaries, Longevity: The Fundamental Driver of Retirement Risks. Illinois 2006: Schaumburg

Stark, D and L. Bruszt, Post-Socialist pathways. Cambridge 1998: Cambridge Univ. Press.

Wilmoth, J. and P. Ball, 'The population debate in American popular magazines, 1946-90'. Population and Development Review, no 18(4), 1992, pp. 631-668. 